\title{
O FANTASMA DO “MONOLINGUISMO” CONTINUA RONDANDO: DIZERES SOBRE A(S) LÍNGUA(S) DO/ NO BRASIL E SUJEITO SURDO
}

\section{THE GHOST OF "MONOLINGUALISM" IS STILL AROUND: SAYINGS ABOUT THE LANGUAGE(S) OF/ IN BRAZIL AND THE DEAF SUBJECT}

\author{
Angela Correa Ferreira Baalbaki \\ Universidade do Estado do Rio de Janeiro, UERJ, Rio de Janeiro, RJ, Brasil \\ Lívia Letícia Belmiro Buscácio \\ Instituto Nacional de Educação de Surdos, INES, Rio de Janeiro, RJ, Brasil
}

Resumo: Tendo em vista os dizeres sobre o sujeito e as línguas no Brasil, percebe-se que ainda ressoam sentidos em defesa de um monolinguismo e, por sua vez, produzem modos de silenciamento e apagamento (AUROUX, 1992; ORLANDI, 1998,1997). Considerando a noçấo de "discurso de" e "discurso sobre" (ORLANDI, 1990), analisaremos dizeres da e sobre a Libras, nas políticas linguísticas e educacionais, mobilizados do lugar do presidente e primeiradama e das relaçôes estabelecidas nestes lugares com as línguas. Dedicamo-nos a analisar tais dizeres produzidos sobre um grupo linguístico minorizado em diferentes materialidades significantes, quais sejam: em mídia digital, em pronunciamento oficial e no Decreto $\mathrm{n}^{\mathrm{o}}$. 9.465/19.

Palavras-chave: Educação para surdos; Análise de Discurso; História das Ideias Linguísticas; Políticas linguísticas.

Abstract: From the observation of statements about the subject and languages in the Brazilian, one can notice that meanings advocating monolingualism still resonate and, consequently, they produce modes of silencing and deletion (AUROUX, 1992; ORLANDI, 1998,1997). Considering the notions of "discurso de" and "discurso sobre" (ORLANDI, 1990), we analyze sayings in and about Libras, in linguistic and educational policies, mobilized from the President's and First Lady's positions regarding languages. We will focus on such statements produced about a linguistic group that has its minority condition exposed in different significant materiality: in digital media, in official pronouncement and decree \#. 9.465/19.

Keywords: Deaf Education; Discourse Analysis; History of Linguistic Ideas; Language Policy. 


\section{Introduçáo}

A constituição discursiva do sujeito surdo brasileiro está posta em relaçáo com as línguas presentes em sua história. De fato, são diferentes os modos como a história predispóe a relaçáo dos sujeitos com a(s) língua(s) e os instrumentos legais que podem instaurar discursividades sobre as línguas, incidindo, inclusive, nas práticas e formulações sobre o ensino. Dessa forma, nota-se em relação à língua de sinais e à língua nacional em território brasileiro, um discurso sobre as línguas instaurado pela Lei 10.436/02, em que a Língua Brasileira de Sinais é dita como "meio de comunicação objetiva e de utilização corrente das comunidades surdas do Brasil", não podendo "substituir a modalidade escrita da Língua portuguesa". Tal discursividade reverbera no Decreto 5.626/05, que dispóe sobre o acesso e o direito à educação e à saúde por surdos, bem como a formação de instrutores, docentes e tradutores-intérpretes, entre outras questóes. Em tal instrumento legal, se pode ler um dizer filiado a um imaginário da relação entre Libras e pessoa surda - "por ter perda auditiva, compreende e interage com o mundo por meio de experiências visuais, manifestando sua cultura" (Cap. I, Art. 2) - e um efeito para a Língua Portuguesa, sobretudo no âmbito do ensino - "modalidade escrita da Língua Portuguesa, como segunda língua para alunos surdos ... em uma perspectiva dialógica, funcional e instrumental" (Cap. IV, Art. 15). Nessa discursividade, é projetado um efeito de bilinguismo em relação à educação de surdos, uma "educação bilíngüe: Libras - Língua Portuguesa como segunda língua” (Cap. III, Art. 11, I). Tais dizeres, pautados em saberes de certo campo da Linguística, incorporam um discurso sobre a educação de surdos. É um discurso que transita para além do educacional, fluindo em movimentos sociais e nas redes sociais, assinalando uma discursividade sobre sujeito surdo e as línguas ${ }^{1}$.

Ainda que um discurso sobre "bilinguismo" incida nos instrumentos legais e no contemporâneo cenário da educação de surdos, é possível notar que ressoam sentidos sobre um monolinguismo, os quais, por sua vez, produzem efeitos em direção ao apagamento de línguas não-instrumentalizadas ou em processo de gramatização, como é o caso da Libras. Tais processos de disputa linguística na tensão com um imaginário de unidade nacional insistem, conforme Guimarães (2005a), pois:

O Brasil é um país multilíngue. Esta característica linguística é significada

${ }^{1}$ Sobre movimentos sociais e sujeito surdo, ver Caldas, Baalbaki e Buscácio(2020). 
politicamente pela tensão histórica entre um imaginário de unidade, comum a um grande número de países contemporâneos, e uma divisão das línguas e de seus falantes. Esse imaginário de unidade é parte da construção das identidades nacionais modernas. (GUIMARĀES, 2005a, p. 22).

Dessa maneira, as condições de produção que forjaram um cenário de diversidade linguística brasileira são da ordem da disputa entre as línguas em retesamento com um imaginário de língua nacional - essa tensão reverbera ainda nas relaçóes de desigualdade entre as línguas e os grupos linguísticos na sociedade e, por sua vez, é reproduzida também na escola.

Consideramos complexas e opacas as relaçóes que se estabelecem entre língua, escola e sujeito. Propomos, portanto, observar como essas relaçôes atuam nos processos de constituição de um imaginário de sujeito surdo, desencadeando certos modos específicos de discursivizaçáo da(s) língua(s) minorizada(s), em certas dimensóes inusitadas, em seus muitos modos de funcionamento e em seus lugares diversos. A partir dessa visada, nosso artigo fundamenta-se no arcabouço teórico da Análise de Discurso materialista em articulação com a História das Ideias Linguísticas, buscando observar a relação entre sujeito surdo entre-línguas, marcado por políticas linguísticas e acontecimentos linguísticos que produzem efeitos de sentido para as línguas minorizadas, como a língua de sinais, na relaçáo com o efeito de unidade linguística, em torno do português como língua nacional.

No cenário multilíngue ${ }^{2}$ brasileiro, é importante ressaltar que, se por um lado, a Língua Portuguesa passa a dividir o espaço de enunciação nacional com línguas de comunidades minorizadas, por outro, a Língua Portuguesa se sobressai politicamente nessa configuração. Devemos lembrar que "[a] questão da língua é, portanto, uma questão de Estado" (GADET; PÊCHEUX, 2010 [1981], p. 37), que é (re)tomada, evidenciada e, muitas vezes, também silenciada. Tendo essa questão como bússola, buscamos constituir nosso arquivo considerando, conforme Orlandi (1990), as noçôes de "discurso de" e "discurso sobre" em relação à Língua Portuguesa, à LIBRAS e ao sujeito surdo, marcadas nos lugares do presidente e da primeira dama, em distintos materiais. $\mathrm{O}$ corpus foi constituído por: pronunciamento da posse presidencial proferido em Libras por Michelle Bolsonaro, primeiro discurso em posse presidencial em língua de sinais; publicaçáo sobre o dia do surdo feita no Twitter de Jair Bolsonaro e o decreto no ${ }^{\circ}$. 9.465/19. Para

${ }^{2}$ Optamos pela designaçáo multilíngue neste artigo, sem nos filiarmos a uma ideia de justaposição de várias línguas ou de subsumir às relaçôes de tensão entre as línguas em um espaço-tempo de comunicaçáo (Cf. SILVA, 2013). 
tanto, foram recortadas sequências discursivas organizadas conforme eixos temáticos para a análise das posiçóes-sujeito (PFEIFFER, 2000) e dos efeitos de sentidos.

O artigo está dividido em cinco seçôes. Exporemos nas duas primeiras seções as noçôes teóricas que baseiam nosso gesto de leitura, mais especificamente, as noçóes teóricas que baseiam nosso gesto de leitura: Disputas entre línguas por lugares de produçáo de sentidos em um espaço multilíngue e Uma relaçáo fantasmática nas políticas de línguas em terras brasileiras. Em seguida, serão expostas as nossas análises sobre o arquivo: $O$ pronunciamento na posse presidencial e nas redes mobilizando dizeres na e sobre a Língua Brasileira de Sinais - Libras e Discurso sobre as línguas em relaçáo a um sujeito surdo nos documentos legais. Por fim, encaminhamo-nos para as Consideraçóes finais, no escape de um efeito de conclusão.

\section{Disputas entre línguas por lugares de produção de sentidos em um espaço multilíngue}

Considerando a possibilidade de outras relações, as línguas que coabitam o espaço multilíngue brasileiro parecem disputar um lugar na memória discursiva pela produção de sentidos, pelo status de poder dizer e poder fazer. Assim, uma tensão entre-línguas pode constituir um sujeito em sua cisão, ainda mais reforçada pelo funcionamento do "sujeito-de-direito" que está longe de se configurar tal qual é imaginariamente construído (universal, livre, responsável). Na luta entre as línguas por espaços de dizer, discursividades em várias direçôes são produzidas a partir das políticas linguísticas, não restritas aos documentos oficiais, que se configuram enquanto materialização dessa disputa. No âmbito da Análise de Discurso, podemos dizer que

a noção de política linguística adquire outro sentido. Ao se definir que a língua se fala, com que estatuto, onde, quando, e os modos de acesso a ela - pelo ensino, pela produção de instrumentos linguísticos, pelo acesso a publicaçôes, pela participação em rituais da linguagem, pela legitimação de acordos, pela construção de instituiçóes linguísticas - está-se praticando as várias formas das políticas de língua, ao mesmo tempo em que, para identificá-la, está-se produzindo seu conhecimento, sua análise, e dando a ela configuração singular. (ORLANDI, 2002, p. 125-126). 
Com isso, podemos afirmar que a Análise de Discurso compreende, conforme Mariani (2004), a política linguística como um funcionamento duplo do político na materialidade linguística: a política de línguas, expressa por documentos, decretos e outras formas de planejamento linguístico, realizada por meio do institucional, e o político na língua, marca da formação ideológica na tensão entre as posições-sujeito. Tal funcionamento do político é atravessado por diferentes constituições do silêncio na língua.

Dentre as formas de silêncio caracterizadas, Orlandi (2007 [1992]) define que uma delas é a política do silêncio, na qual duas formas têm existência ligada: o silêncio constitutivo (dizer $\mathrm{X}$ para não dizer $\mathrm{Y}$, isto é, ao dizer $\mathrm{X}$ necessariamente é preciso silenciar $\mathrm{Y}$ ) e o silêncio local, sob forma de censura (não permitir o dizer $X$ proferido por alguém). A censura pode tanto levar ao apagamento do dizer do outro, interditando sentidos como forma de sobrelevar um discurso dominante, quanto suscitar variadas formas de resistência do oprimido. Tendo em vista que o território brasileiro abriga centenas de línguas, as políticas linguísticas em relação à produção de seus instrumentos linguísticos e aos seus processos de legislação são capturadas pelo funcionamento do silêncio - seja o constitutivo, seja o da censura -, no discurso sobre as línguas minorizadas em tensão com a língua dominante.

Em um espaço multilíngue, especificamente no caso do nosso país, a presença de outras línguas pode produzir instabilidade e polêmicas (PFEIFFER, 2001) em torno da língua nacional. Historicamente, observamos vários movimentos de apagamento dessas polêmicas, como se outras línguas fossem "menos-língua" ou sequer existissem. De acordo com Pfeiffer (2001),

\footnotetext{
Sabemos que é parte constitutiva de todo processo de organização social em torno de uma unidade identitária a busca por uma unidade linguística. Por sua vez, é parte constitutiva de todo processo de legitimação de uma língua o apagamento de outras línguas que estão em funcionamento em uma dada sociedade (PFEIFFER, 2001, p. 182).
}

Segundo a autora, o processo de gramatização de línguas, funcionando como instrumento de estabilizaçáo, leva ao estancamento de tais línguas. E, seria a escrita a que poderia promover, em alguma medida, o processo de gramatização. Pfeiffer (2001) complementa que é na escrita que "há a legitimaçáo de uma forma linguística em confronto com várias outras que estão em funcionamento em um mesmo espaço linguístico. E nesta materialidade da escrita irrompem conflitos destas línguas" (PFEIFFER, 
2001, p. 169). Há um processo de apagamento das outras línguas que são apresentadas apenas sob a forma da oralidade e, acrescentaríamos, da sinalização. Ou seja, línguas sem escrita não teriam o mesmo status e reconhecimento de língua nacional, uma vez que a escrita parece lhe imputar legitimidade e unidade. Afinal,

para que haja gramática é preciso que haja o efeito de unidade da língua e este é construído no processo de gramatização em uma relação circular línguaslíngua-gramática, balizada pela escrita que, por sua vez, é conformada por uma memória discursiva em que um de seus sentidos é recoberto pela própria ideia de urbanidade (PFEIFFER, 2001, p. 180).

Tal processo está imbricado ao papel da escrita na instrumentalização das línguas. A escrita, para Auroux (1998), é antes de tudo um saber técnico construído sobre um saber epilinguístico. $\mathrm{O}$ autor delega à escrita um lugar privilegiado no desenvolvimento dos fatos linguísticos e a inscreve no núcleo da produção do conhecimento sobre a linguagem. Ainda destaca as relaçóes das instâncias de poder e os domínios de funcionamento da escrita, já que: "o escrito só aparece e se mantém em sociedades fortemente hierarquizadas, e entretém desde a origem (e, sobretudo, na origem) relaçôes muito estreitas com as diversas instâncias de poder" (AUROUX, 1998, p. 68). Ainda, conforme o autor, o funcionamento da escrita é impulsionado não apenas por essa demanda interna (das instituiçôes políticas), como também pela necessidade de apreensão da língua do outro, do estrangeiro, como estratégia de dominação.

Uma vez considerada a relação necessária entre a constituição da escrita e o processo de gramatizaçáo - entendido como "o processo que conduz a descrever e instrumentar uma língua" (AUROUX, 1992, p. 65) - pode-se compreender como a gramatização transforma os processos de dominaçáo sobre outros povos - e acrescentamos aqui, entre diversos grupos sociais. No caso da Libras, o processo de gramatização encontra-se em pleno andamento, ainda há poucos instrumentos linguísticos sobre a Língua Brasileira de Sinais, o que incide nos modos de circulação da língua no ensino e nas políticas linguísticas a ela relacionadas.

Dessa maneira, a constituiçáo do espaço de enunciação brasileiro, considerado como esse espaço de funcionamento de "línguas, que se dividem, redividem, se misturam, desfazem, transformam por uma disputa incessante" (GUIMARÁES, 2005b, p.18), se dá na tensão continuada entre a língua dominante, dotada de escrita, que vai assumir os papéis imaginários 
de língua nacional e língua oficial, e a resistência, oferecida pelas línguas minorizadas - como é o caso da Libras.

A política do bilinguismo (na relação entre Libras e Língua Portuguesa) para os surdos, nesse cenário, parece se formar como uma espécie de acordo entre a tendência monolinguista advinda do imaginário de unidade nacional, que faz sobreporem as formas imaginárias das língua materna, nacional e oficial (cf. GUIMARÃES, 2005a), e os interesses dos grupos linguísticos minorizados como os surdos, cuja Libras adquire o estatuto de "meio legal de comunicação e expressão" (BRASIL, 2002), mas não chega a se constituir plenamente como língua oficial.

Cabe, então, questionar até que ponto um imaginário de bilinguismo, enquanto política linguística, favoreceria uma língua minorizada (e a comunidade a ela relacionada) em detrimento de outras, considerando um espaço multilíngue, como é o caso brasileiro. Por outro lado, ainda que haja políticas linguísticas que tentem operar pela inversão, supondo a inversão pela Libras em relação à Língua Portuguesa do/no Brasil materializada nos documentos oficiais sobre a língua e a educação, não há a possibilidade de que o bilinguismo se dê de forma harmônica entre as línguas. Em outras palavras, que bilinguismo seria esse para os sujeitos surdos? Um bilinguismo para os surdos encamparia o discurso do outro sobre as línguas do/no Brasil? O que é silenciado no discurso sobre o bilinguismo para surdos em relação às outras línguas presentes no território brasileiro?

\section{Uma relaçâo fantasmática nas políticas de línguas em terras brasileiras}

Parafraseando Pêcheux (1990), o fantasma do monolinguismo parece continuar a rondar... O que estaria presente/ausente nas atuais políticas linguísticas endereçadas aos sujeitos surdos sinalizantes? Como se daria a política linguística secular da imposição de uma única língua em relação à língua de sinais, língua distante em sua forma de produção (sinalizada) e sua historicidade, em muito interditada por marcar nela e por ela um grupo outro desprestigiado e tomado como não-eficiente? Sobre a língua de sinais, Fernandes (2007) comenta:

[a] língua de sinais é a manifestação de uma forma de linguagem verbal, por meio de palavras sinalizadas, que difere de país para país, sofre mudanças históricas e é passível de variaçóes regionais e/ou sociais [...] um idioma convencional com regras estruturais e de funcionamento próprias 
(FERNANDES, 2007, p. 3).

Como apontam Baalbaki e Caldas (2014), a partir de 2000, iniciase um processo de cooficializaçáo de línguas de grupos minorizados em âmbito municipal no Brasil. No caso específico da Libras, observamos um movimento que estava atrelado também ao processo de legalização de língua de sinais em vários países, principalmente, aqueles membros da Organização das Naçóes Unidas - ONU (DE MEULDER, 2015). Como foi já dito, o marco da legalizaçáo da Libras entra em vigor com a lei $\mathrm{n}^{\circ}$ 10.436/2002, produzindo um efeito de reconhecimento do status legal dessa língua como meio de comunicaçáo e expressão da comunidade surda. Vale lembrar que esse acontecimento legal foi possível após anos de luta da comunidade surda. Segundo o artigo $1^{\circ}$, parágrafo único, da referida lei:

\footnotetext{
Entende-se como Língua Brasileira de Sinais - Libras a forma de comunicação e expressão, em que o sistema linguístico de natureza visualmotora, com estrutura gramatical própria, constitui um sistema linguístico de transmissão de ideias e fatos, oriundos de comunidades de pessoas surdas do Brasil (BRASIL, 2002).
}

Com a promulgação da lei e com o decreto, é conferido um estatuto de legalidade à língua de sinais em território brasileiro, o que reverbera na formação de certo imaginário sobre a Libras (promovendo a circulação de saberes e ideias sobre essa língua) e sobre o sujeito surdo. A Libras passa a ser significada como "meio de expressão" das "comunidades de pessoas surdas" e, em consequência, servir como "meio de instrução" para aprendizado de conteúdos escolares, em um discurso sobre a Libras marcado pela contradição de caracterizá-la como meio de comunicação e de instrução, já que a denominação "língua" comparece apenas para designar seu nome - Língua Brasileira de Sinais. E, como vimos, a modalidade escrita da Língua Portuguesa é discursivizada nos instrumentos legais enquanto uma segunda língua para os sujeitos surdos, dizer que é também assinalado pela contradiçáo, pois, como já citamos, a "Libras não poderá substituir a modalidade escrita da língua portuguesa" (Lei 10.436/05). Que efeitos são produzidos então por um status de segunda língua para Língua portuguesa, sobretudo no ensino? Por essa discursividade, é difundida uma constatação de que seria necessário mudar o processo educacional do aprendiz surdo. Segundo Baalbaki e Caldas (2014): 
Desde então, novos saberes circulam em ambientes acadêmicos, fazendo que a língua circule, ao menos, nos espaços institucionais de formação de professores de educação básica. Em função da política de inclusão dos alunos surdos às instituiçóes de ensino em geral, passou a ser obrigatória a presença do intérprete de LIBRAS em sala de aula, e a língua principiou a ter presença oficial nas escolas e a ser conhecida mais de perto também por ouvintes. Por outro lado, também há obrigatoriedade do ensino da Língua Portuguesa na modalidade escrita aos surdos, gerando um efeito que caracteriza a LP como uma língua de madeira nesse contexto (BAALBAKI; CALDAS, 2014, p. 81).

Por língua de madeira, no caso, entende-se o funcionamento que promove, de maneira política, a denegaçáo da política, como espaço de confronto advindo da desigualdade de estatutos no âmbito das sociedades ditas democráticas. Dita como "segunda língua", a Língua Portuguesa, uma língua a ser aprendida pelo surdo e ligada à escolarizaçáo, no caso da escrita, e à fonoaudiologia, no caso da modalidade oral, pode funcionar como uma língua de madeira porque o aprendizado linguístico se apresenta como um privilégio de classe, na gestáo da ordem pública e no acesso aos meios de informaçáo, conferindo-lhe um efeito de língua opaca, por antes reforçar a exclusão do surdo do que por lhe promover o acesso. Acesso esse, convenhamos, também na ordem do imaginário.

Desta maneira, se, por um lado, os saberes educacionais e linguísticos advindos de campos de pesquisa e de militância ligada à comunidade surda estáo materializados nas políticas de um imaginário de uma educação dita bilíngue para surdos; a política linguística ecoa nos saberes educacionais sobre sujeito surdo, produzindo um efeito discursivo da Língua Portuguesa na tensão de ser ensinada como uma segunda língua para surdos brasileiros, subsumida a um imaginário de unidade, de língua nacional.

Faz-se necessário trazer o corpus que possibilita nosso gesto de leitura. Dessa maneira, pretendemos, com base no quadro teórico de referência, averiguar as discursividades inscritas em dizeres da e sobre a Libras, por vezes reforçado e legitimado pelo lugar do representante político. Para tanto, faz-se necessário trazer as noções de "discurso de" e "discurso sobre", que, conforme Orlandi (1990), operam na memória discursiva pela tensão entre posiçôes. Segundo a autora, o "discurso sobre" configura-se em "uma das formas cruciais da institucionalização dos sentidos", elevando determinada posição discursiva no efeito de legítima e evidente, em detrimento de outras posiçóes, produzindo um efeito de unidade em determinado dizer, como se não houvesse um modo distinto de dizer. Tal funcionamento é reforçado 
pelo "discurso de", que opera de modo a alçar um lugar de autoridade, de poder dizer. Por outro lado, há possibilidade de um dizer outro habitar o "discurso sobre", em um movimento da memória: ao mesmo tempo em que um efeito de legitimidade destaca certa posição e lugar, o "discurso sobre" também abriga diferentes "discursos de", e "é um lugar importante para organizar as diferentes vozes (dos discursos de)" (ORLANDI, 1990, p. 37).

De modo a estabelecer um recorte do arquivo discursivo (ORLANDI, 1984), seguimos Pfeiffer (2000) sobre o eixo enunciativo, o qual é constituído de várias enunciaçôes que vêm de uma mesma posição-sujeito, depreendidas a partir do dispositivo analítico. Nesses eixos, percebemos tanto uma concorrência de sentidos como possibilidade de deslizamento de sentidos. Desta maneira, o corpus é constituído pelo discurso de Michele Bolsonaro na posse presidencial, que no lugar de primeira dama proferiu o discurso em Libras, algo inédito nesta língua e em uma posse presidencial, pela publicação no Twitter de Jair Bolsonaro no Dia do Surdo e por artigos e parágrafos referentes à comunidade surda do Decreto 9465/19, um dos primeiros decretos de Jair Bolsonaro no lugar de presidente. O documento versa sobre a regulamentação e a organização de órgãos públicos e de ministérios, produzindo "sentidos de governança" (ORLANDI, 2012b, p. 133).

Ressaltamos que há diferenças entre o pronunciamento, a mensagem pelo aplicativo Twitter e o instrumento legal. Sáo textualidades distintas, com formas de circulação também distintas. No entanto, consideramos "um corpus discursivo como um conjunto de sequências discursivas" (COURTINE, 2009 [1981], p. 54). Para recortar as sequências discursivas (SDs), buscamos regularidades que nos ajudassem a pensar como a Libras é significada na cena multilíngue e como são discursivizados os posicionamentos em relação à Libras e ao sujeito surdo (entre-línguas).

Com o recorte, buscaremos analisar se é possível verificar como certos sentidos são fixados ou excluídos, como os efeitos de sentido podem ventilar um imaginário sobre mono/bi/multilinguismo, em um discurso sobre Língua Portuguesa e a Libras de um lugar autorizado a legislar, o lugar da presidência. Nossos gestos de análise seguem nas duas próximas seçôes.

\section{O pronunciamento na posse presidencial e nas redes sociais mobilizan- do dizeres na e sobre a Língua Brasileira de Sinais - Libras}


Nesta seção, traremos duas sequências discursivas para nossa análise: trechos do pronunciamento da primeira dama na posse presidencial em 2019 e uma postagem no Twitter oficial do presidente Jair Bolsonaro referente ao Dia do surdo. Ambas as sequências se referem ao funcionamento do discurso do lugar do presidente.

A seguir, recortamos o pronunciamento primeira-dama na posse presidencial, em 2019 para formar a SD1.

SD1:

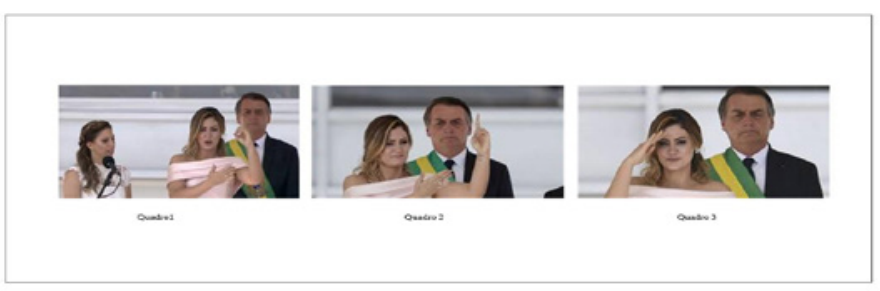

Figura 1: Série de trechos do vídeo do pronunciamento de Michelle Bolsonaro na posse presidencial (2019)

Fonte: https://www.youtube.com/watch?v=qUUp57m-PHc

O pronunciamento, em relação às suas condições de produção, foi marcado por certas singularidades: a presença de uma intérprete de Libras; a posição física do presidente (atrás da primeira-dama) e, sobretudo, por ser produzido entre a Libras e a Língua Portuguesa (oral e escrita). Esse gesto de produzir um pronunciamento na posse presidencial na língua de um grupo minorizado pode ser analisado como um acontecimento discursivo (PÊCHEUX, 2008 [1988]) que ressignifica, ainda que localmente, o estatuto imaginário da Libras: trata-se do primeiro discurso presidencial proferido em língua de sinais no Brasil. Consideramos que a materialidade linguística da produçáo e seus efeitos institucionais, mais do que procedimentos comunicacionais inovadores, podem ser considerados um acontecimento discursivo - entendido como "um ponto de encontro entre uma atualidade e uma memória” (idem, p.17) —, tendendo a promover rupturas e abrindo novas regiōes de sentido.

Além de instaurar a presença de uma língua outra, de grupo minorizado, na cerimônia de posse presidencial, a posição dianteira da primeira-dama, 
Michele Bolsonaro, confere um duplo lugar à figura feminina e à Libras, na política. Por um lado, o pronunciamento em Libras ganha destaque visual (ao invés de se encerrar nas costumeiras janelas com intérpretes no canto das imagens televisionadas) e uma presença; promovendo uma ruptura ao projetar uma mulher que se expressa em uma língua de grupo minorizado e, provavelmente, desconhecida por muitos, uma primeira dama no lugar de saber sobre a língua e, neste imaginário, de ser porta voz de um grupo linguístico. Cabe destacar que a intérprete também reforça esse ideário de mulher protagonista pelo lugar de saber sobre a língua. Por outro lado, como analisaremos, é um dizer que circula sobre duas sinalizaçôes: बी D, de Deus; B, de Bolsonaro. Desta forma, neste dizer, um imaginário para um lugar de mulher protagonista que detém um saber sobre a língua opera na ordem da contradição por estar inscrito em diferentes ordens.

Devido à materialidade significante da Libras ter caráter espaço-visual, é preciso explicitar que a maneira como foi registrada a SD1 difere, por exemplo, de sequências recortadas em Língua Portuguesa. Selecionamos, em consideração à dimensão temporal espacial (com movimento e direção) do pronunciamento em Libras, "instantes" do texto como índices que propiciam a recuperaçáo das sequências discursivas recortadas para a análise. Em suma, recortamos o intradiscurso: a formulaçáo do dizer produzida pela língua de sinais (ou seja, os elementos linguísticos se dáo visualmente no espaço para fins de construçáo do fio discursivo). Além disso, a Libras é marcada pelo fato de a língua ser produzida no corpo do sujeito enunciador (afinal, o corpo e o seu espaço correlato sáo tomados com o suporte material da língua), o que pode levar a confundir o sujeito empírico com a posiçãosujeito. Lembramos que, do ponto de vista discursivo, a língua é a base material dos processos discursivos. Logo, as línguas de sinais também são. Compreender esse ponto da materialidade linguística é importante, visto que língua e história se transpassam; produzem simultaneamente uma forma linguístico-histórica. Destarte, "a forma material (não abstrata como a da linguística) que é a forma encarnada na história para produzir sentidos" (ORLANDI, 2001, p. 19). Em suma, pensar no modo como o pronunciamento constituiu uma textualidade específica tendo como materialidade a Libras permitiu-nos elaborar uma forma distinta de recorte em três quadros.

$\mathrm{Na}$ SD1, capturamos dois sinais que marcaram o pronunciamento: o sinal de deus e o de Bolsonaro. Observamos a produção do signo "deus" em 
Libras, nos dois primeiros quadros da SD1, cuja descrição do sinal pode ser:

configuração de mão em

(D), palma para frente no espaço neutro (em frente ao peito), movimento retilíneo e inclinado que sai do espaço neutro e vai para a parte lateral superior da cabeça ${ }^{3}$. Como estaria significando esse sinal no pronunciamento?

Do campo da Antropologia social, Assis Silva (2012) discute a circulação de agentes com trajetória neopentecostal na disciplinarização de corpos surdos. O autor destaca como a Libras emerge, a partir do início deste século, como a língua dos surdos que deve ser utilizada para a sua evangelizaçáo, ligada a grupos neopentecostais filiados a um discurso no campo da teologia que produz um imaginário de prosperidade e predestinaçáo. A concepção da surdez como minoria linguística e a prática tradutória são mobilizadas para justificar o trabalho de evangelismo neopentecostal, marcado historicamente com proselitismo em línguas de grupos minorizados (indígenas, por exemplo). Nesse bojo, a Libras, o intérprete e, completamos, o estar no lugar de saber sobre a língua de sinais, são entendidos como recurso de acessibilidade para a evangelizaçáo.

Em parte, essa relação está materializada no bordão que caracteriza o governo Bolsonaro, "Brasil acima de tudo, Deus acima de todos", enunciado em Libras e em Língua Portuguesa. Assim, uma "posição-sujeito presidente" (ORLANDI, 2012b, p. 133), promove a palavra do governo na língua do Estado (ORLANDI, 2012b): a Língua Portuguesa permanece com os sentidos de língua nacional; a Libras, uma língua outra tolerada pela Língua de Estado, passa a funcionar na mesma rede de "museificaçáo de línguas exóticas" (ORLANDI, 2014, p.18), de que se vale um discurso sobre o bilinguismo pelo Estado. Como, em AD, considera-se que é no processo da produção de sentidos que o sujeito se constitui e por estar atrelado a uma posição-sujeito que sentidos são produzidos - temos aqui a palavra "Deus" ressignificada pelo lugar da primeira-dama agregado a um caráter teocrático do governo; fazendo emergir à memória discursiva que relaciona Libras à evangelização do surdo no Brasil.

O sinal de Bolsonaro, no terceiro quadro da SD1, isto é, o nome de Bolsonaro em Libras, atribuído pela comunidade surda, tem a seguinte descrição linguística: configuração de mão em $(\mathrm{OM})$ (B), palma para baixo, 
com ponto de articulação na lateral da testa, com movimento arredondado ascendendo até o alto da cabeça. Esse sinal pode ser lido em uma mesma cadeia do sinal de "soldado" ou "militar" orientaçáo e pelo movimento da mãos. De forma geral, o pronunciamento da primeira-dama parece ser atravessado e sustentado por dizeres filiados a certa vertente do cristianismo, neopentecostal, ligada a um imaginário de predestinaçáo e de prosperidade, enlaçado a um dizer do militar.

Tais dizeres retornam materializados nas redes sociais vinculadas ao lugar do presidente. Publicado no Twitter vinculado ao perfil oficial de Jair Bolsonaro, vejamos o recorte que forma a SD2:

SD2: 26 de setembro, Dia Nacional do $\underline{\text { Surdo. }}$ Temos buscado valorizar cada vez mais os deficientes auditivos, dando atenção especial ao grupo, incluindo tradução em libras em nossas lives e eventos, e conhecendo melhor as demandas. Um forte abraço a todos! ${ }^{6}$

Um efeito metafórico (PÊCHEUX, 1997[1969]), isto é, um fenômeno semântico produzido por uma substituição contextual na qual uma palavra é substituída por outra pode ser destacado na SD2: surdo por deficiente auditivo. Esse deslizamento pode chegar a um termo distante do primeiro, mas que guarda com aquele primeiro uma memória de sentido. Que memória seria? O deficiente auditivo estaria ligado à memória da incapacidade, produzida, em grande medida, por certo saber médico advindo de uma formação discursiva positivista ${ }^{7}$ ?

Observamos uma contradição: ao mesmo tempo em que se enuncia "dia do surdo", enuncia-se outra categorizaçáo desse sujeito pela marca da "deficiência". A atenção distinta ao grupo (deficiente) ocorreria pela inserção da tradução em Libras. Cabe ainda perguntar sobre a discursividade analisada: a condição de diferença linguística do surdo estaria sendo considerada ou seria a traduçáo (e a própria Libras) um meio (um código simplificado) para

${ }^{4}$ Como em toda língua, o sinal pode fluir de modos distintos, gerando outros significantes. $\mathrm{O}$ sinal de militar, por exemplo, também é manifestado pela "mão direita com a palma da mão para dentro diante do ombro esquerdo se move ligeiramente para cima, abre e toca o ombro esquerdo, como a representar alegoricamente uma patente militar ali fixada" (CAPOVILLA \& RAPHAEL, 2009, p.506).

${ }^{5}$ Sobre os parâmetros de descrição da Libras, ver BRITO (1995).

${ }^{6}$ Disponível em: https://twitter.com/jairbolsonaro/status/1177234966570250240, publicado em 26 de setembro de 2019, 11 h54.

${ }^{7}$ Sobre uma formação discursiva positivista, ver Orlandi, 2002. 
transmitir certos conteúdos e não outros? Se o sujeito é deficiente, seria a Libras considerada língua ou só uma forma diferente de comunicação (no rol das várias linguagens)?

Se como Assis Silva (2012), consideramos que a Libras é tomada como recurso de acessibilidade para evangelização neopentecostal, também podemos dizer que na SD2, a língua de sinais parece servir como recurso de acessibilidade para inserção do surdo na narrativa governamental. Se por um lado a interpretaçáo das lives e demais pronunciamentos promovem a inclusãa ${ }^{8}$ do sujeito surdo (e atentem normativas internacionais sobre formas de inclusão - sobretudo, aquelas discursividades advindas de tratados internacionais), por outro, promovem o controle das narrativas políticas, uma vez que não abrem espaço para a polissemia. A língua seria concebida, táo somente, pelo caráter instrumental, apagando sua opacidade, a historicidade, o equívoco. Um possível funcionamento da museificação de uma língua a que se refere Orlandi (2014), uma língua minoritária tolerada porque serve como instrumento de acessibilidade para a difusão de um discurso do Estado, um Estado que projeta um bilinguismo (Língua Portuguesa/Libras) e apaga as línguas outras que habitam o território brasileiro - retomando os dizeres em Bolsonaro, não haveria espaço para “outra língua”. Passemos à análise do Decreto 9465/19.

\section{Discurso sobre as línguas em relaçáo a um sujeito surdo nos documen- tos legais}

O Decreto no 9.465, de 2 de janeiro de 2019, que "aprova a estrutura regimental e o quadro demonstrativo dos cargos em comissão e das funçóes de confiança do Ministério da Educação" (BRASIL, 2019) e remaneja outros cargos e funçôes de confiança do mesmo órgão, é constituído por uma ementa, dez artigos e um anexo. Assumimos que decretos como esse são práticas discursivas e podem ser pensadas em termos de efeito de regularidade administrativa, nos cargos de administração pública do executivo federal- a partir de "sentidos de governança" (ORLANDI, 2012b, p. 133). Talvez uma das mudanças em relação aos decretos anteriores, que versam sobre a mesma matéria legislativa, seja a inserção da Secretaria de

${ }^{8}$ Compreendemos inclusão como "um movimento que deflagra a inclusão enquanto incentivo à participaçáo e acesso de todos a determinados espaços sociais, como uma grande rede que se tece em torno de políticas e práticas conectadas aos interesses e conveniências do modo de vida neoliberal" (MEDEIROS, 2014, p. 77). 
Educação Bilíngue. A seguir, trazemos a ementa do decreto.

No Anexo 1, capítulo II, sobre a estrutura organizacional do Ministério da Educaçáo, na alínea F, do $3^{\circ}$ artigo, tem-se o estabelecimento de divisão em três diretorias da Secretaria de Modalidades Especializadas de Educação. Uma dessas diretorias é a Diretoria de Políticas de Educação Bilíngue de Surdos. Detalhadamente, no art. $35^{\circ}$, do mesmo anexo, encontra-se a competência desta diretoria, elencando algumas atribuiçôes. Para fins de nossas análises, recortamos alguns trechos e os inserimos abaixo.

\begin{abstract}
SD 3: I - planejar, orientar e coordenar, em parceria com os sistemas de ensino voltados às pessoas surdas, com deficiência auditiva ou surdocegueira, e com as instituiçóes representativas desse público, a implementação de políticas de educação bilíngue, que considerem a Língua de Sinais Brasileira (Libras), como primeira língua, e Língua Portuguesa Escrita, como segunda língua ;

II - fomentar a criação de Escolas Bilíngues de Surdos, em todo o território nacional, com oferta de educaçáo integral, em todos os níveis, etapas e modalidades de ensino;

VI - promover a transversalidade e a intersetorialidade da educação bilíngue, visando a assegurar o pleno desenvolvimento linguístico-cognitivo e a aprendizagem dos estudantes surdos, surdocegos e deficientes auditivos;

VIII - promover o acesso a programas de educação linguística precoce e identificação de bebês surdos, por meio de parcerias com órgãos da área da saúde e da assistência social; (BRASIL, 2019)
\end{abstract}

Interessante verificar os verbos no infinitivo que iniciam cada uma das atribuiçôes: planejar, orientar, coordenar, fomentar, promover. Verbos que estão atrelados a certas competências e a um engendramento de dizerfazer vinculados à possibilidade de "desenvolvimento" e "aceleração de crescimento" de certas áreas, como um projeto de "educação bilíngue" por "Escolas bilíngues de surdos". Esse dizer-fazer (ou dizer-quase-fazer) é característico do funcionamento da política linguística e mostra uma contradiçáo materializada no documento legal.

Percebemos no decreto um imaginário para o lugar de estudante dessa "Escola bilíngues de surdos" em categorias: "surdos, surdocegos e deficientes auditivos". Parece-nos que "de surdos" aponta para uma escola projetada sem que o sujeito seja a finalidade mas, sim, a referência a sua especialidade - afinal, não se trata de uma escola para surdos, mas de uma escola de surdos. Outro efeito possível seria o de uma escola onde um saber alçado como verdadeiro viria de um surdo idealizado por essa 
discursividade, sem necessariamente estar relacionado a um campo de saber para a escola. Seria um bom sujeito surdo - no lugar de professor, de estudante - que sobreporia outras posiçóes sujeito ao ocupar um lugar de privilégio hierárquico no espaço escolar, em detrimento das possibilidades de contribuiçóes de distintos campos de saber. Dito de outra forma, seria uma escola de estudantes classificados em uma dessas categorias, pressupondo apenas uma relação entre a Libras (L1) e a Língua Portuguesa (L2), advinda de um saber de certo ramo dos Estudos Surdos. Nesse saber, são silenciados sentidos outros para um sujeito no lugar de estudante na relação entre a Libras, a Língua Portuguesa e, por que não dizer, as línguas e linguagens outras. Assim, consideramos que outras possibilidades estariam abertas para um sujeito surdo, visto em sua relação entre-línguas, já que

afetado pelo simbólico (por um simbólico que vai se ampliado) e pego pelo real das línguas não terá como evitar se significar pelos sentidos que desatam os dois significantes e pela fricção que eles promovem entre si. [...] Cada um deles sugerirá a esse sujeito movimentos específicos, inclusive contraditórios, afetando-o de modo diferente, e tramará sequências com fios que fazem parte de uma história dividida entre dois espaços de enunciação (CELADA, 2013, p.66)

Além disso, na SD3, no trecho "programas de educação linguística precoce e identificação de bebês surdos", verificamos o modo como certo discurso médico marca a memória discursiva sobre um imaginário de educação bilíngue. Embora haja uma menção à atuação integrada de "órgãos da área da saúde e assistência social", não comparece no artigo ${ }^{\circ}$ 35 as várias inscriçóes sociais possíveis que incidem no lugar do estudante surdo: não é dito sobre a vulnerabilidade social, não se fala sobre a questão racial, tampouco, da orientação sexual. Além disso, o decreto não menciona outras possibilidades de questóes físicas, psíquicas e neurológicas que podem constituir um sujeito surdo e precisam de planejamento e açóes efetivas a partir de conhecimentos produzidos por parte de variados campos de saber (médico, pedagógico, sociológico, etc.), de modo a colaborar com a saúde do sujeito dentro e fora da escola. Assim, se por um lado, há um discurso médico que se inscreve na memória da educação de surdos, recuperando uma rede de saberes que constitui modelos tradicionais de educaçáo especial baseados na noção de deficiência, de outro, saberes médicos ligados ao saber social que poderiam comparecer para contribuir para outro olhar em prol da saúde do estudante são silenciados.

Ainda, pelo decreto, a "educação linguística precoce" parece não 
estar vinculada a áreas ligadas à questão das línguas e linguagens. Falar em "educação linguística precoce" retoma, em algum grau, a condição de possibilidade de inscrição do sujeito surdo no simbólico. Uma entrada que, em muitos casos, é marcada pela própria historicidade de uma língua interditada, que afeta a relaçáo de familiares (na maioria ouvintes) de surdos com a língua de sinais, e, por sua vez, a constituição do sujeito surdo na e pela linguagem, No decreto, a não inserção de especialistas da área da linguagem também pode contribuir para tal interdição, uma vez que por serem reduzidas as pesquisas na área de Estudos da Linguagem que versam sobre línguas de sinais e que pouco circulam socialmente, certos dizeres médicos podem prevalecer - provavelmente, pelo maior prestígio social atribuído a esse campo de saber ${ }^{9}$. Além disso, faz-se urgente considerar de que maneira a situação de vulnerabilidade socioeconômica que marca grande parte das famílias brasileiras e, por conseguinte, famílias de surdos, pode afetar sintomaticamente na relação com as línguas, bem como no acesso à educação e à saúde, entre outros ${ }^{10}$. Em suma, a proposta de parceria com as áreas de saúde e assistência social ao não ser estendida à área da linguagem, entre outros aspectos, náo dá visibilidade a esse saber, o que pode acarretar em um declínio na relaçáo precoce de surdos com a Libras. Destacamos aí também a possibilidade de funcionamento do "discurso sobre", alçando determinado dizer em cada campo de saber - a saúde, a assistência social etc - em detrimento de outros.

Passemos ao artigo no 34 que se refere à "Diretoria de Acessibilidade, Mobilidade, Inclusão e Apoio a Pessoas com Deficiência”. Vejamos a SD4:

SD4: V - formular e implementar políticas para apoiar os sistemas de ensino na inclusão de estudantes com deficiência, transtornos globais do desenvolvimento e altas habilidades ou superdotação e favorecer o acesso, a permanência e a aprendizagem nas instituiçóes educacionais em ambientes que maximizem seu desenvolvimento acadêmico e social. (BRASIL, 2019)

\footnotetext{
${ }^{9}$ Por exemplo, como se pode ler materializado no discurso jornalístico, ainda é forte na área médica indicar a cirurgia para implante coclear ao diagnosticar bebês surdos, como pode ser visto na matéria "Crianças surdas recebem implante coclear pelo SUS", veiculada pelo Jornal EPTV, em 22 de agosto em 2019. Disponível em: http://g1.globo.com/mg/sul-deminas/jornal-da-eptv-2edicao/videos/t/edicoes/v/criancas-surdas-recebem-implante-coclearpelo-sus/7864145/. Nota-se uma divisão na área: entre orientar um uso restrito da Língua portuguesa oral e reconhecer o papel da Libras, o que se verifica em: http://g1.globo.com/ sp/sao-carlos-regiao/noticia/2013/03/conhecer-libras-faz-implante-coclear-ser-mais-beneficodiz-fonoaudiologa.html. No entanto, o debate sobre o tema não se encerra, de forma alguma, nesses exemplos. Há fatores de classe, bioéticos, entre outros, que fogem ao escopo deste artigo. ${ }^{10}$ Ver Silva, Kauchakje e Gesueli (2003).
} 
Ao direcionar a "inclusão de estudantes com deficiência", o artigo $\mathrm{n}^{\circ} 34$ instaura uma intercessão com o artigo $\mathrm{n}^{\circ} 35$, ao se encontrar "com deficiência" e ser "deficiente auditivo": designaçôes atribuídas pelo determinado discurso médico para o lugar de estudante surdo. Ou seja, um dizer sobre a escola inclusiva atravessa um dizer sobre a escola bilíngue de surdos, retomando uma discursividade da educação especial para dizer sobre a educação bilíngue de surdos. Um dizer sobre o lugar do estudante "surdo, surdocego e deficiente auditivo" em uma mesma cadeia de "estudantes com deficiência" incide em uma tensão discursiva entre um imaginário de bilinguismo escolar construído para um surdo idealizado usuário de Libras e um modelo de escola inclusiva para "estudantes com deficiência".

De certa forma, então, surdos não são interpretados como uma minoria linguística, mas um grupo deficitário, "deficiente", a quem se concede o ensino, em geral, o de Língua Portuguesa, em particular, sob o regime da dominação, agora: Língua Portuguesa / ouvinte - "normal" e Libras / surdo - "deficiente". Com isso, reforça-se mais uma vez o "fantasma do monolinguismo" que paira. Afinal, não há um estatuto de "sujeito-dedireito" para o sujeito surdo, se levarmos em conta a noção de, sujeito entrelínguas, nas bases de um mecanismo de produçáo de sentidos sobre a língua e políticas linguísticas nas quais esse sujeito é sempre subalternizado em relação à Língua Portuguesa.

\section{Consideraçóes finais}

Ao propormos uma análise dos dizeres que circulam sobre questôes linguísticas, principalmente relacionadas à Língua Portuguesa e a um grupo minorizado, consideramos que o efeito de verdade produzido é reforçado e legitimado pelo lugar do presidente, produzindo na memória do dizer efeitos que ressoam de modo a encobrir (ou até mesmo apagar) outras possibilidades de dizer daquele lugar. Isto é, do lugar do presidente e da primeira-dama, circula um discurso sobre o surdo e as línguas, reforçado pelo funcionamento do efeito de verdade sobre o sujeito e as línguas na memória do estado nacional brasileiro.

Nas quatro sequências recortadas, parece haver a promoção de uma arena discursiva que retoma a tensão entre Estado-nação (uma língua e uma nação) e as várias línguas minorizadas no espaço de enunciação brasileiro. Além de silenciamento e apagamento em prol da unidade da língua do estado-nação brasileiro em relação às demais línguas, observamos que a 
Libras é tomada como língua-tolerada - pela via do assistencialismo ou da difusão da política governamental, marcada, no governar, por uma discursividade neopentecostal, teocrática.

A tensão discursiva nas políticas linguísticas e educacionais no dizer sobre a Libras e sujeito surdo também foi depreendida no documento legal. Ao falar de "escola bilíngue de surdos", no decreto, é difundido um imaginário de identificação do estudante surdo com a Libras e com a Língua Portuguesa escrita. Entretanto, cabe perguntar onde residiria uma possibilidade de outros modos de processos de identificação, inclusive, de não-identificaçáo com a Libras, considerando assim as diferentes posiçóessujeito que podem estar inscritas no lugar de aprendiz de uma escola para surdos.

Ademais, profissionais como professores de línguas e linguagens, linguistas, assistentes educacionais, mediadores e tradutores-intérpretes, fonoaudiólogos, médicos, assistentes sociais, entre outros, não comparecem no decreto. Ressaltamos ainda o decreto no $10.185 / 19$ veta a abertura de concursos públicos para "tradutor intérprete de linguagem de sinais" (sic). Uma divisão do espaço de enunciação no interior de aparelho ideológico do estado. Como implementar políticas de educação bilíngue e promover uma escola bilíngue para surdos, tal como escrito no Decreto, se a Libras sequer comparece como componente curricular na Base Nacional Comum Curricular (BNCC, 2018), e se não há a projeção de contratação de profissionais específicos da área? Sem dúvida, mais uma contradição que aparece em vários pontos das políticas públicas planejadas e assumidas, sobretudo, no lugar do presidente empossado em 2019.

Diante deste cenário crivado pelo paradoxo, é preciso considerar que gestos de resistência produzidos pela comunidade surda sáo atravessados por tensóes que marcam a Libras, já que a cisão é constitutiva do sujeito e, por sua vez, da língua. E, conforme formulamos, se trata da cisão de um sujeito entre-línguas. É um lutar pelas possibilidades de dizer de um sujeito e, principalmente, pela língua, pelas línguas, por um estar entre-línguas. Afinal, como afirma Pêcheux (2004 [1981], p. 33), "A língua, também merece que se lute por ela”.

\section{Referências}

AUROUX, S. A revoluçáo tecnológica da gramatizaçáo. Campinas, SP: 
Editora da UNICAMP, 1992.

. A escrita. In: A Filosofia da Linguagem. Trad. José Horta Nunes. Campinas, SP: Ed. da Unicamp, 1998. p. 63-93.

ASSIS SILVA, C. A. de. Cultura surda: agentes religiosos e a construçáo de uma identidade. São Paulo: Terceiro Nome, 2012.

BRASIL. Lei no 10.436, de 24 de abril de 2002. Dispóe sobre a Língua Brasileira de Sinais - LIBRAS e dá outras providências. Disponível em: <http://www.planalto.gov.br/ccivil 03/leis/2002/110436.htm>. Acesso em: mar. 2020.

BRASIL. Decreto No 5.626. Regulamenta a Lei no 10.436, de 24 de abril de 2002, que dispóe sobre a Língua Brasileira de Sinais - LIBRAS, e o art. 18 da Lei $\mathrm{n}^{\circ} 10.098$, de 19 de dezembro de 2000. Publicada no Diário Oficial da União em 22/12/2005. Disponível em: <http://www.planalto. gov.br/ccivil 03/ ato2004-2006/2005/decreto/d5626.htm>. Acesso em: mar. 2020.

BRASIL. Decreto no 9.465, de 2 de janeiro de 2019, que "aprova a estrutura regimental e o quadro demonstrativo dos cargos em comissão e das funçóes de confiança do Ministério da Educação". Disponível em: <http://www. planalto.gov.br/CCIVIL 03/ Ato2015-2018/2018/Decreto/D9465.htm>. Acesso em: mar. 2020.

BAALBAKI, A. C. F.; CALDAS, B. Como a língua portuguesa se organiza em um espaço de enunciação ampliado. In: BAALBAKI, A.; Caldas, B. (Org.). Instrumentos linguísticos: usos e atualizaçôes. Araruama: Editora Cartolina, 2014, v. 1, p. 75-102.

BRITO, Lucinda Ferreira. Por uma gramática de línguas de sinais. Rio de Janeiro: Tempo Brasileiro, 1995.

CALDAS, B.; BAALBAKI, A. C. S.; BUSCÁCIO, L. L. B. Movimentos sociais, sujeitos surdos e resistência. In: GRIGOLETO, E.; NARDI, F. S.; DELA-SILVA, S.. (Org.). Discursos da resistência: literatura, cultura, política. São Paulo: Pedro \& João, 2020, v. 1, p. 51-77.

CAPOVILLA, F. C., RAPHAEL, W.D. Enciclopédia de Libras - O mundo do surdo em Libras. São Paulo: Edusp, 2009, vol.4.

CELADA, M. T. Linguagem/sujeito. Forçando a barra em língua estrangeira. In: In: CARMAGNANI, A. M. G.; GRIGOLETTO, M. (Org.). Língua, discurso e processos de subjetivaçáo na contemporaneidade. Sáo Paulo: Humanitas, 2013. p. 43-75. 
COURTINE, J-J. Análise de discurso político: o discurso comunista endereçado aos cristãos. Trad. Cristina de Campos Velho Birck et al. São Carlos: EdUFScar, 2009 [1981].

DE MEULDER, M. The legal recognition of sign languages. Sign Language Studies. Washington, v. 15, n. 4, p. 498-506, 2015.

FERNANDES, S. Avaliaçáo em língua portuguesa para alunos surdos: algumas consideraçóes. Secretaria de Estado da Educação. Grupos de estudos por área. Curitiba, 2007. Disponível em: $<$ http://www.diadiaeducacao. pr.gov.br/portals/portal/ins titucional/dee/deesurdez.php>. Acesso em: jun. 2011.

GADET, Françoise; PÊCHEUX, Michel. A língua inatingível: o discurso na história da lingüística. Campinas: Pontes, 2004 [1981].

GUIMARÁES, E. Política de línguas na linguística brasileira. In: ORLANDI, E. (Org.). Política linguística no Brasil. Campinas, SP: Pontes, 2007, p. 63-82.

. Apresentação: Brasil País Multilíngue. Ciência e Cultura, S. Paulo, v. 57, n. 2, p. 22-23, 2005a.

Multilinguismo, divisóes da língua e ensino no Brasil. Campinas: Cefiel/IEL/Unicamp, 2005b.

MARIANI, B. Colonizaçáo linguística. Campinas: Pontes, 2004.

MEDEIROS, C. S. O discurso da inclusão pela diferença na relação mídia e sociedade. In: FERREIRA, E. L.; ORLANDI, E. Discursos sobre a inclusáo. Niterói: Intertexto, 2014. p. 51-88.

ORLANDI, E. P. Ciência da Linguagem e Política: anotaçôes ao pé das letras. Campinas: Pontes, 2014.

Discurso em Análise: Sujeito, Sentido, Ideologia. Campinas: Pontes, 2012.

Análise de Discurso: princípios \& procedimentos. Campinas: Pontes, 2001.

. As formas do silêncio. 4. ed. Campinas: Unicamp, 2007 [1992].

. Língua e conhecimento linguístico. São Paulo: Cortez, 2002.

. Terra à vista. Discurso do confronto: velho e novo mundo. Campinas: Unicamp, 1990.

. "Segmentar ou recortar". In: . Linguística: questôes e controvérsias, publicação do Curso de Letras do Centro de Ciências Humanas 
e Letras das Faculdades Integradas de Uberaba, Série Estudos - 10, 1984. p. 9-26.

PÊCHEUX, M. Delimitaçôes, inversôes, deslocamentos. Cadernos de Estudos Linguísticos, n. 19. Campinas: UNICAMP/IEL, p. 7-24, jul./dez. 1990.

. Semântica e discurso; uma crítica à afirmaçáo do óbvio. Campinas: Unicamp, 2009 [1988].

. Discurso, estrutura ou acontecimento. Campinas: Pontes, 2006 [1983].

. Por uma análise automática do discurso: uma introduçáo à obra de Michel Pêcheux. In: GADET, F e HAK, T. (Org.). Campinas, SP: Editora da UNICAMP, 1993.

PFEIFFER, C. C. A língua nacional no espaço das polêmicas do século XIX e XX. ln: ORLANDI, E. P. (Org.). História das Ideias Linguísticas. Campinas, S.P.: Pontes; Cáceres, MT: Unemat Editora, 2001. p. 167-184.

Bem dizer e retórica: um lugar para o sujeito. 2000. $183 \mathrm{f}$. Tese (Doutorado em Linguística). Universidade Estadual de Campinas, Instituto de Estudos da Linguagem, Campinas, 2000.

SILVA, Ivani Rodrigues; KAUCHAKJE, Samira; GESUELI , Zilda Maria (orgs.). Parte II - Surdez: comunidade e família. Cidadania, surdez e linguagem: desafios e realidades. São Paulo: Plexus, 2003. p. 55-112. 